\title{
Derleme
}

Spor

\section{Sporun Psiko-Motor Gelişim ve Sosyal Gelişime Etkisi}

\author{
Emre Yildı1 ${ }^{1}$ Zeynep Çetin ${ }^{2}$ \\ ${ }^{1,2}$ Hacettepe Üniversitesi, Sağllk Bilimleri Fakültesi, Çocuk Gelişimi Bölümü
}

\begin{abstract}
Özet
Spor, hareket içeren ve bireylerin sosyal çevrelerini genişleten bir olgudur. Bireyler, spor sayesinde sosyal ortamlarda nasıl davranmasına ilişkin bazı sosyal becerileri gözlemleme firsatı bulurlar. Hareket içeren spor, aynı zamanda motor becerileri de destekler. Çocuklar için de motor beceriler okul öncesi dönemde; oyunlarındaki rolü ve mutluluğu açısından önemlidir. Okul öncesi dönemdeki bu beceriler okul döneminde çocuğun ilgisi doğrultusunda sporda branşlara yönlendirilebilmelerinde temel oluşturacaktır. Çocuklar spor yaptı̆̆ında hem motor becerileri hem de sosyal becerileri desteklenmiş olacaktır. Aynı zamanda daha çok insanla tanışıp, aynı sosyal ortamı paylaşma firsatı bulacaklardır ve böylelikle kişilerarası iletişim, gruba dâhil olma, kendini tanıma ve sınırlılıklarını fark etme, kazanma-kaybetme gibi duyguları yaşayıp öğrenme, kendini ifade etme, özgüven kazanma gibi becerileri de spor yaparken kazanma firsatları olacaktır. Bunlara ek olarak spor yapmanın gelişimsel olarak katkısının yanı sıra insanların içinde yaşadıkları toplumda verimli, sağlıklı ve mutlu olmalarında önemli bir rol oynar. Yukarıdaki bilgilerden yola çıkılarak bu makalede de sporun psiko-motor ve sosyal gelişimle etkileşimi irdelenmiştir.
\end{abstract}

Anahtar Kelimeler: Spor, Psiko-motor Gelişim, Sosyal Gelişim

Sorumlu Yazar: Emre Yıldız, Hacettepe Üniversitesi, Sağlık Bilimleri Fakültesi, Çocuk Gelişimi Bölümü, 6. Kat. Sihhiye/ANKARA. e-mail: emreeyldz06@gmail.com.

*Bu derleme makale, I. Uluslararası Beden Eğitimi, Spor, Rekreasyon ve Dans Kongresi'nde sözel bildiri olarak sunulmuş̧ur.

Gönderim Tarihi: 25 Mayis, 2018

Kabul Tarihi: 19 Ekim, 2018 
Review

Sport

\title{
Psycho-Motor Development and Social Development Impact of Sports
}

\author{
Emre Yildı1 ${ }^{1}$ Zeynep Çetin ${ }^{2}$ \\ ${ }^{1,2}$ Hacettepe University, Faculty of Health Sciences, Department of Child Development
}

\begin{abstract}
Sports is a phenomenon involving movement and expanding the social environment of individuals. Individuals have the opportunity to observe some social skills about how to behave in a social environment through sports. Sport with motion, supports motor skills at the same time. Motor skills for children are also pre-school; It is important for the role and happiness of the games. These skills in the pre-school period can be directed to the branches in the direction of the child's interest during the school period. When children play sports, both motor skills and social skills will be supported. At the same time, they will have the opportunity to meet more people and share the same social environment and thus they will have the opportunity to acquire skills such as interpersonal communication, group participation, self-awareness and recognition of limitations, experiencing and learning feelings such as winning and losing, self-expression, self-confidence while playing sports. In addition to their developmental contribution to sport, they also play an important role in enabling people to be productive, healthy and happy in their communities. Based on the above information, this article examines the interaction of sports with psychomotor and social development.
\end{abstract}

Key Words: Sport, Psychomotor Development, Social Development

Corresponding Author: Emre Yıld1z. Emre Yıld1z, Hacettepe University, Faculty of Health Sciences, Department of Child Development, 6 ${ }^{\text {th }}$ floor. Sihhiye/ANKARA. e-mail: emreeyldz06@gmail.com.

*This review paper had been presented as an oral presentation in the $1^{\text {st }}$ International Congress of Physical Education, Sport, Recreation and Dance.

Submission Date: $25^{\text {th }}$ of May, 2018

Acceptance Date: $19^{\text {th }}$ of May, 2018 


\section{Giriş}

Gelişimin temelleri anne karnından itibaren atılmaktadır. Bu bağlamda bu dönemden itibaren çocukların gelişim dönemleri ne kadar sağlıklı olursa ileriki dönemlerde de sağlıklı olacağı yadsınamaz bir gerçektir. Çocukların erken dönem gelişim dönemlerinde temel olarak sevilme, beslenme, güven içinde hissetme gibi gereksinimlerinin yanı sıra hareket etme ve oyun oynama gibi gereksinimleri de vardır. Özellikle çocukların bu gelişim süreçlerinde ve gereksinimlerinde en temel ihtiyaçlarından birisinin hareket becerileri olduğu düşünülebilir. Hareket becerileri doğumla başlayıp, büyüme ve gelişmeyle birlikte basit refleksiften karmaşı̆̆a doğru devam eden bir süreçtir (Tepeli, 2012).

Çocukluk döneminde hareket, kimi zaman isteklerin ifade edilmesinde kimi zaman eylemi yerine getirmede kimi zaman oyun oynarken önemli olan becerilerin başında gelir. Oyun, çocuğun yaşamını etkileyen önemli bir olgu olduğu ve oyun oynarken hareket becerileri de gerektiği için, hareket kabiliyeti, çocuğun oyun içindeki mutluluğunu ve rolünü belirleyen önemli olan unsurların başında gelir. Dolayısıyla çocuk oyun oynarken hareket eder ve bu hareketliliği ilerleyen yaşlarında belli kurallar ve amaçlar doğrultusunda yönlendirildiğinde hem eğlenir hem sosyalleşir.

Bedensel hareketlenmenin öğrenmeyi aktif bir sürece geçirdiği bilinmekle birlikte aynı zamanda oyun oynayan çocuğun becerilerini de geliştirmektedir (Arabacı \& Çıtak, 2017).

Aynı şekilde sporun, bireylerin hareket ihtiyaçlarını karşılayan, belli kuralları olan, eğlendiren, sosyalleştiren; kendi içinde rekabete dayanan fiziksel aktiviteler olduğu ifade edilmektedir (Heper ve ark., 2012).

Çocuklar spor yaparken etkileşim içinde olurlar ve belli kuralları öğrenirler. Bir işi yapma, üstlenme bilincinde olurlar. Takım sporu yaparken ise bir takım sosyal kuralları öğrenirler ve bu sosyal kurallar çocuğun toplum içinde ve diğer çocuklar arasında kabul edilmesi ve benimsenmesi açısından kolaylık sağlayabilir.

Çocukların dünyayı algılayıp tanımalarında bedenlerini kullanarak edindikleri deneyimler oldukça önemlidir. Bundan dolayı motor gelişim, bilişsel gelişim ve algısal gelişim birbirleriyle iç içedir. Özellikle yaşamın ilk yıllarında kazanılan deneyimler motor gelişim, sosyal-duygusal gelişim ve bilişsel gelişimin alt yapısını oluşturmaktadır. Örneğin; topu kalenin içine gol atan bir çocuk ayak-göz-beden koordinasyonu sağlayıp denge becerisini geliştirirken, çocuğun başarma duygusuyla kendine güveni dolayısıyla da sosyal-duygusal gelişimi de desteklenmiş olur. Topun yuvarlak olduğunu öğrenmesiyle de bilişsel gelişimi desteklenmiş olur (Bayhan \& Artan, 2009). Örnekten de anlaşılacağı üzere, hareket ile ilgili bir eylem ile 
birçok gelişim alanı desteklenebilmekte ve gelişim alanları birbirlerini doğrudan etkilemektedir.

Bu makalede; psiko-motor gelişim ve sosyal-duygusal gelişim alanları ele alınıp bu gelişim alanları ile sporun etkileşiminin incelenmesi amaçlanmıştır.

Psiko-motor gelişim, yaşam boyunca devam eden, motor becerilerde meydana gelen değişimleri inceleyen süreci ifade etmektedir. Bu sürecin incelenmesi de basitten zora veya kompleks hareketlere doğru devam edecek şekilde olacaktır (Demirci, 2007).

\section{Psiko-motor Gelişim Aşamaları}

Gallahue, motor gelişim dönemini, kuramında; piramit şeklinde açıklamıştır. Bu modele göre motor gelişim 4 başlık altında incelenmiştir (Gallahue, 1982):

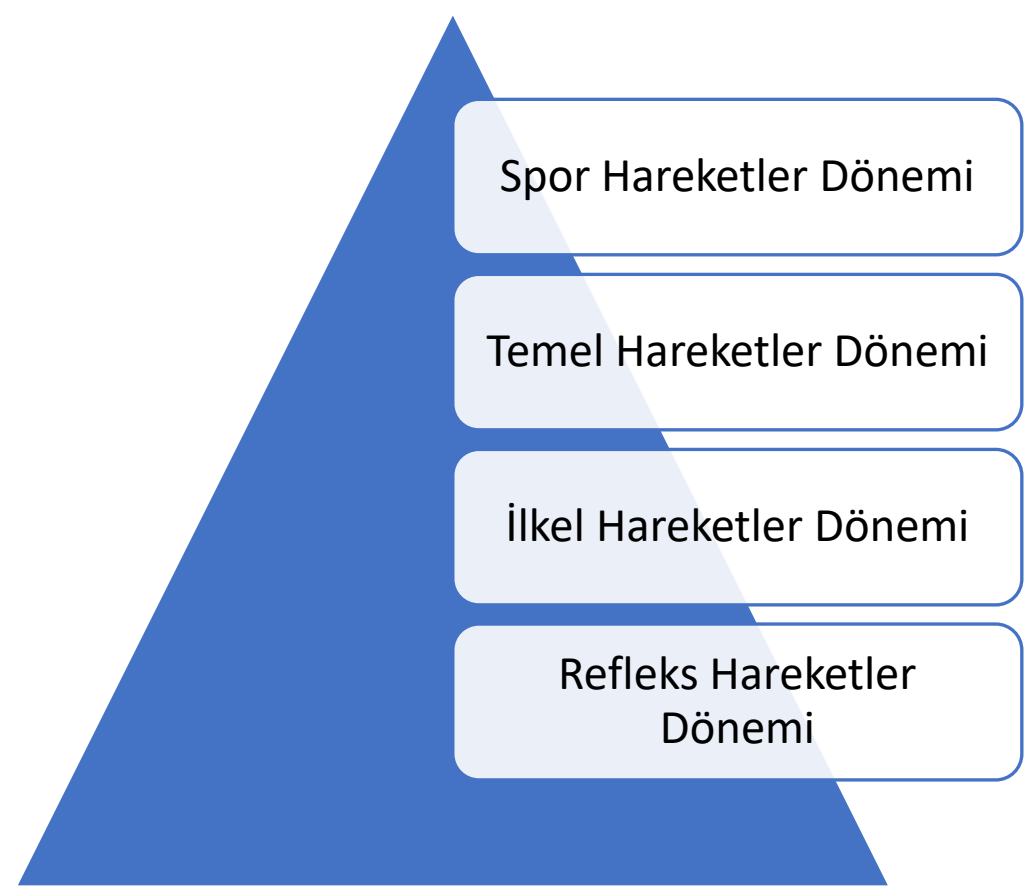

\section{Refleks Hareketler Dönemi}

Yeni doğan bebeklerin motor becerileri oldukça aktiftir. Bu dönem öncelikle refleksleri daha sonrasında ise istemli hareketleri içerir. Bebekler refleksleri, bilgi edinmek amaciyla kullanırlar. Reflekslerin olmaması, az veya güçsüz olması nörolojik bozuklukların nedeni olabilir. Fakat bilinmelidir ki bu dönemde görülen nörolojik sonuçlar ileride olabilecek bozuklukların açık bir şekilde göstergesi olmamaktadır (Şahin, 2016). Bu evre 2 aşamadan oluşmaktadır. Birincisi; doğum öncesinden başlayıp 4. aya kadar devam eden bilgi toplama 
aşamasıdır. İkincisi ise; refleks hareketlerin ortadan kalkmaya başlayıp oturma, kalkma, emekleme gibi amaçlı hareketlerin ortaya çıktığı aşamadır (Gallahue, 1982).

\section{İlkel Hareketler Dönemi}

Refleks hareketler döneminden sonra gelen ve 0-24 ay aralığını kapsayan dönem ilkel hareketler dönemidir. İlkel hareketler olarak tabir edilen hareketler; denge hareketleri, manipülatif hareketler ve lokomotor hareketlerdir. İlkel hareketler olgunlaşmayla beraber gelişir ve çocuktan çocuğa, çevresel ve kalıtsal etmenlere bağlı olarak değişir. Gallahue bu dönemi kendi içinde 2 evreye bölmüştür. Birincisi; reflekslerin ortadan kalktığı evre, İkincisi ise ilk kontrol evresidir. Birinci evre olan reflekslerin ortadan kalktığı evrede, hareketler artık bir amaca yönelik olarak gelişir ancak kontrol tam anlamıyla sağlanamaz. Bu nedenle bu evrede hareketler daha kabadır. İkinci evre olan, ilk kontrol evresi ise 12-24 ay aralığını kapsayan dönemdir. Bu dönemdeki bebek bir önceki döneme göre daha profesyonel hareketler sergiler ve hareketlerini kontrol etme eğilimindedir. Sırasıyla; elinden tutunca yürür, bağımsız yürür, merdivenleri dört ayak pozisyonunda çıkar, koşar şeklinde belirtilebilir (Şahin, 2016).

\section{Temel Hareketler Dönemi}

Bu dönemde kazanılan beceriler; yakalama, topa vurma, firlatma, atlama, zıplama gibi becerilerdir. Bu beceriler her bireyin yaşamını sürdürmesi için gerekli olan becerilerdir. $\mathrm{Bu}$ nedenden dolayı temel beceriler olarak nitelendirilmektedir (Şahin, 2016).

Gallahue ve Ozmun, becerileri 3 evreye bölmüşlerdir; Acemilik, başlangıç ve olgunluk. Örneğin sek sek oyununu bir çocuk 3-4 yaşında acemilik, 5-6 yaşındaki bir çocuk başlangıç, 7 yaşındaki bir çocuk olgunluk seviyesinde oynayabilir. Yapılan bu hareketler çocuğun yaşına göre değil hareketi yaptığı seviyeye göre değerlendirilmedir. Bazı çocuklar becerileri erken bazıları ise daha geç yapabilirler. Temel hareketlerin ediniminde çevresel faktörler kadar bireysel faktörler de etkilidir (Gallahue \& Ozmun, 1995).

\section{Sporla İlgili Hareketler Dönemi}

$\mathrm{Bu}$ evre, temel hareketler döneminin bir uzantısı olarak görülür ve spor hareketlerle gelişir. Bu dönem daha çok amaçlı hareketlerin gerçekleştiği dönemdir. Bir önceki dönemde yapılan beceriler, bu dönemde kurallarla birleşip, işbirliğine dayanan etkinliklere dönüşebilir. Örneğin bir önceki dönemde kazanılan sekme ve zıplama becerileri bu dönemde daha kurallı 
ve işbirliğine dayanan ip atlama oyununa dönüşebilir. Veya hareket eden topa vurabilme becerisi, bu dönemde kurallı ve işbirliğine dayalı futbol oyununa dönüşebilir (Tepeli, 2012).

$\mathrm{Bu}$ dönemde, çocukların yetişkinler tarafından motor becerilerinin kontrolü için yönlendirilmesi son derece önemlidir. Sporun tüm branşlarından artık spesifik bir branşa doğru yönlendiği evredir. Gallahue ve Ozmun (1995)'a göre bu dönem, çocuğun kendi yeterliliklerinigüçlü ve zayıf yönlerini keşfedip, belirli bir branşa yöneldiği dönemdir. Bu dönem, daha önceki dönemlerin en son aşamasını oluşturmaktadır (Gallahue \& Ozmun, 1995).

Aynı zamanda Milli Eğitim Bakanlığı (MEB) da hareket eğitimine önem vermiş ve bu eğitimle ilgili olarak (Okul Öncesi Eğitim Programı/Etkinlik Çeşitleri ve Açıklamaları) da şu ifadelere yer vermiştir (MEB, 2013):

' 'Hareket etkinliğinin amacı, çocukların temel hareket becerilerini geliştirerek çocuğun fiziksel, motor, bilişsel, dil, sosyal ve duygusal, gelişimine ve öz bakım becerilerine katkıda bulunmaktır. Böylece çocuğun fiziksel etkinliklere yaşam boyu katılımı da sağlanabilir. Çocukların fiziksel ve motor yeterliliklerinin, algısal motor gelişimlerinin ve hareket becerilerinin yani yer değiştirme, nesne kontrolü ve denge becerilerinin geliştirilmesini içeren etkinliklerdir. Bu etkinlikler süresince çocukların temel hareket becerileri, beden farkındalığ motor yeterliliği (güç, koordinasyon, hız, çabukluk) ve fiziksel yeterliliği (esneklik, kuvvet, dayanıklılık) gelişir. Örnek etkinlikler: Beden farkındalığını (bedenin omuz, bel, dirsek ve bilek gibi değiş̧ik bölümleri), alan farkındalığını (yukarı, aşağı, ön, arka, sağ, sol gibi), kuvvet, hız, çabukluk, esneklik, dayanıklılık ve koordinasyonu geliştirici etkinlikler, yapılabilecek etkinlikler arasındadır. Çocukların bireysel özelliklerini dikkate alan, onları güdüleyici, benlik algılarını ve özgüvenlerini pekiştirici etkinliklere yer verilmelidir. Uygulamalarda çevre düzenlemesine, çocukların yaşlarına uygun ve temel hareket becerilerini kazandırmada etkili olacak materyaller seçilmesine özen gösterilmelidir. Etkinliklerde top, ip, tebeşir, hullahup, denge tahtası gibi yapılandırılmış materyaller gibi açık hava oyun materyallerinin kullanımına ek olarak doğanın çocuklara sunduğu farklı yapıdaki zeminler, tırmanma olanakları, denge için kullanılabilecek kütükler gibi materyal ve ortamlar da kullanılmalıdır. Ayrıca geleneksel/yöresel çocuk oyunlarının, açık havada oynanan sokak oyunlarının da hareket etkinlikleri kapsamına dâhil edilmesi etkinlikleri çeşitlendirecektir. Hareket etkinliği, çocukların motor gelişimlerinin desteklenmesi ve hareket becerilerinin kazandırılması amacıyla ele alınabileceği gibi geçiş etkinliği olarak da uygulanabilir. Bu durumda yapılacak çalışmalar için etkinlik planı hazırlanmasına ve bunların günlük eğitim akışına yazılmasına gerek yoktur. Etkinlikler en az 30 dakika sürmeli bu sürenin ilk 5 dakikası 1sınma oyunları, 20 dakikası bir 
önceki uygulamanın tekrarı ve yeni temel hareket becerileri, son 5 dakikası da soğuma etkinlikleri olmalıdır. Hareket beceri etkinlikleri sınıf içinde veya açık havada, bahçede uygulanabilir."

\section{Sosyal Gelişim}

Sosyalleşme, yaşamın ilk yıllarından başlayarak devam eden bir süreci içine alan bir olgu olup, çocuğun aile içinde desteklenmesi ileriki yaşantısında sosyal bir birey olmasına katkı sağlayacak önemli faktörlerdendir (Günindi, 2010). Bu bağlamda çocukların hayata uyum sağlamalarında sosyal-duygusal gelişim çok önemlidir. Çocukların sosyal yetenekleri; akran ilişkilerinin, çevresel uyumlarının yönünü ve şeklini belirler. Problem çözme, kurallara uyma, karar verme, kendini yönetme ve kişilerarası ilişkiler gibi sosyal yeteneklerde başarılı olan çocukların çevreleriyle sosyal uyumu da yüksek olur. Çocuklar içinde bulundukları çevre ile doğrudan veya dolaylı olarak etkileşim içinde bulunarak sosyal yeteneklerini geliştirebilirler (Şahin, 2016).

Saarni (2001), sosyal duygusal gelişimi, çocuğun kendini ifade edip, davranışlarını kontrol edebilmesi, çevresiyle uyumlu ve barış içinde olabilmesidir, şeklinde ifade etmiştir.

Sosyal becerilerle ilgili alan yazına bakıldığında; sosyal davranışların çeşitli değişkenlerle etkileşim içinde olduğu görülür. Özellikle anne-baba-çocuk ilişkisi, sosyal becerilerin kazanılması ve sürekliliği ailede ve çocuğun içinde bulunduğu tüm çevrede başlayıp, tekrar edilmesiyle gerçekleşir (McClelland \& Morrison, 2003).

Çocuklar, sosyal kuralları ve sosyalleşmeyi erken çocukluk döneminde öğrenirler. Sosyalleşme, çocukların akranları veya kardeşleri aracılığı ile gelişir (Culbertson, Newman, \& Willis, 2003).

Sosyal yeteneklerinin gelişmesi için çocuklara akranları ile beraber vakit geçirecekleri zamanlar ve alanlar oluşturulmalıdır. Çünkü çocuklar en iyi şekilde ancak birbirleriyle baş edebilirler (Şahin, 2016).

$\mathrm{Bu}$ çerçevede sportif faaliyetlere çocukların ekibin bir parçası olarak katılmaları; yardımlaşma, sorumluluk alma, düzenli ve birlikte çalışma, kurallara uyma ve diğer ekip elemanlarının haklarına saygı duyma gibi sosyal becerilerin ve duyguların geliştirmesini etkilemektedir (Güven, 2006).

Durualp de oyun gibi fiziksel etkinliklerin, çocukların sosyal becerileri üzerine etkisini incelemiş ve oyun temelli sosyal beceri eğitimine katılan deney grubundaki çocukların sosyal uyumlarının daha yüksek olduğunu bulmuştur. (Durualp \& Aral, 2010). 
Findlay (2006)'de çocukların spora katılımlarının daha yüksek pozitif etki, sosyal becerileri ve mutluluk durumları da dâhil birçok beceriyi etkilediğini bulmuştur. Spora katılan utangaç çocukların da sosyal kaygılarında azalma olduğunu saptamıştır.

Salar, Hekim, ve Tokgöz (2012)'ün yaptığı araştırmaya göre 15-18 yaş grubunda spor yapan çocukların sakin, toplumla uyumlu ve kendine güveni yüksek olduklarını bulmuştur.

Spor kişilerin hareket ihtiyaçlarını karşılayan, eğlendiren, sosyalleştiren ve daha birçok nedenden dolayı tercih edilen; branşlar içeren ve her branşın kendine özgü kuralları olan, çoğunlukla rekabete dayanan fiziksel hareketlerin tümüdür (Heper ve ark., 2012).

Spor, çocuğun duygusal, sosyal ve fiziksel gelişimi için önemli bir etkinliktir. Okul öncesi dönemde sporun, çocuğun fiziksel ve psikolojik yapısı göz önünde bulundurularak, fiziki yapısını ve duygusal durumunu destekleyecek, toplumsal kuralları öğrenmesine destek olacak oyun yapısında olması gerektiği vurgulanmaktadır (akt.Çelik ve Şahin, 2013).

Erken çocuklukta kazanılan lökomotor ve nesne kontrol becerileri, bir sonraki çocukluk evresinde oyun ve spor gelişimine katkı sağlar (akt. Özyürek, Özkan, Begde, ve Yavuz, 2015).

Çocuklar altı yaşında gelişimsel olarak tüm hareketleri yapabilir durumda olmalı ve bunları motor gelişiminin spor yönüne aktarmaya başlamalıdır. Çocuklar hareketleri yaparken cesaretlendirilmemesi, yeteri kadar şans verilmemesi ve yetersiz öğretim nedenlerinden dolayı geri kalmaktadırlar (Şimşek, 1998).

Erken yaşlarda fiziksel aktivitelerle büyüyen çocuklar için spor, temel gereksinimler olan yemek gibi, su gibi, uyumak gibi bir gereksinimdir. Temel hareket becerileri gelişmiş olan çocuklar, daha özel beceri gerektiren alanlara da hazır olacaklardır. Okul öncesi dönem ve ilkokulun ilk yılları temel hareketlerde profesyonel olmak için çok önemli yıllardır (Özer ve Özer, 2016).

Temel hareket becerilerinin gelişimi, çocuklarda küçük ve büyük motor kas becerilerinin gelişmesiyle beraber kasların koordineli bir şekilde çalışmasına olanak sağlar, bedensel farkındalık yaratır ve spor kültürünün oluşmasını sağlar. Sistemli ve belli bir amaç dâhilinde yapılan hareketler ise hızlılık, güç, dayanıklılık gibi becerilerin gelişmesinin yanı sıra atlama, zıplama, koşma gibi lökomotor hareketlerin de gelişimini destekler. Spor yaparken bir grup içinde yer alan çocuk, sosyal becerilerinin gelişmesi adına önemli bir firsata sahip olabildiği gibi; spor kurallara uyma, empati kurma, kendine güvenme ve problem çözme becerilerinin de gelişmesine olanak sağlar. Bu becerilerin yanı sıra sporun sağlık için de faydası vardır (akt. Özyürek, Özkan, Begde ve Yavuz, 2015). Çocuklar spor yaparken enerjilerini de atmış olup, duygusal olarak da rahatlama yaşarlar (akt. Özyürek, Özkan, Bedge ve Yavuz, 
2015). Spor, kendi sınırlarını fark etmesine, hangi hareketleri yapıp hangilerini yapamayacağına, hangi hareketlerde ne derece iyi olduğuna karar vermesine olanak sağlar. Aslında çocuk, spor yaparken kendini tanıma imkânı bulmuş olur.

Yılmaz ve Bozkurt (2017), '’Oyun ve Fiziki Etkinlikler Dersinin İlkokul Öğrencilerinin Motorik Özelliklerinin Gelişimine Etkisi'"ni inceledikleri çalışmada,9-10 yaş grubundan 52 çocukla çalışmışlardır. 29 çocuk deney grubunu, 23 çocuk ise kontrol grubunu oluşturmuştur. 6 hafta boyunca 1 ders saati kadar yürütülen uygulamalarda bazı fiziksel etkinliklerde bulunulmuş, deney ve kontrol gruplarının ön test-son test sonuçları incelenmiştir. Son test sonuçlarına göre deney grubu ve kontrol grubu karşılaştırıldığında, deney grubunun fiziksel etkinliklerde kontrol grubuna göre daha iyi olduğu saptanmıştır.

Aynı zamanda Şenduran (2008) da 183 çocukla yürüttüğü çalışma sonucunda; düzenli spor yapan öğrencilerin kendileri ve çevreleriyle daha fazla uyum içinde ve kendileriyle daha barışık olduklarını bulmuştur.

Çocukların sağlıklı bireyler olarak yetişmelerinde fiziksel çevreler de çok önemlidir (Arabacı \& Çıtak, 2017). Ancak artan şehir yaşantısı ve yoğun araç kullanımı çocukların hareket edecek alanlarının kısıtlanmasına neden olmaktadır. Hareket alanı azalan çocuğun algısal motor beceri gelişimi sekteye uğrayabilmektedir (Tüfekçioğlu \& Ayça, 2008).

Artan şehirleşme ve çarpık kentleşmeyle beraber, çocuklar kendilerine oyun alanı bulmakta zorlanmaktadırlar. Bu da çocukların evlere, okullara ve yuvalara hapsedilmesine ve başarıya zorlanmasına neden olmaktadır. Ve böylelikle aslında eğlence üzerine kurulu oyun ticari bir hal almaya başlamaktadır. Çocukların 'dışarıda oyun' diye tabir edilen oyunları, aslında 'kamusal' alan yerine 'özel' alanlarda olmaktadır. Bu nedenle çocuklar, ebeveyn gözetimi olmaksızın, kamusal alanları tanımaktan ve vakit geçirmekten uzak kalmaktadırlar (Valentine \& Mckendrickt, 1997).

Günümüz çocuklarında hareketsiz yaşam tarzının arttığı ve bu durumun çocuklarda birçok sağlık problemine neden olduğu bilinmektedir (Hekim, 2016).

Çocukların teknolojik aletlerle fazlaca vakit geçirmeleri ve bu esnada oturuyor olmaları bazı sağlık problemlerini de beraberinde getirmektedir. Bunlardan bazıları; vücut duruş bozukluğu, kilo artışı, kas kaybı vb. gibi. Bu nedenlerden dolayı çocukların sportif faaliyetlere katılması gelişimleri açısından önemlidir (Saka, Yıldız, Tekbaş, \& Aydın, 2008). 


\section{Sonuç ve Öneriler}

Spor, insanların yaşamında doğrudan yer almış ve çocukların psiko-motor ve sosyal gelişimlerine katkısı olan sosyal bir olgudur. Sporun vücudumuza fiziksel faydasının yanı sıra, birçok gelişim alanını desteklemesiyle çocuk gelişimine de faydası vardır.

Çocuklar, doğumlarından itibaren artan bir sosyal çevre ile ilişkilerini dengelemede, yönlendirmede ve sosyal becerilerini geliştirmede spordan faydalanabilirler. Aynı zamanda spor içlerindeki enerjiyi atmaları ve hareket ihtiyaçlarını karşılamak adına önemli bir fırsattır.

Bebeklik döneminde reflekslerle başlayan psiko-motor gelişim; ilkel hareketler, temel hareketler ve spor hareketler basamaklarındaki becerilerin kazanımıyla sırasıyla devam eder. Okul öncesi dönemde hareket becerileri oldukça önemlidir. Çünkü bu beceriler çocuğun seçeceği oyununu, oyun içindeki mutluluğunu ve akran ilişkilerini önemli ölçüde etkileyen becerilerin başında gelir. $\mathrm{Bu}$ dönemi başarılı bir şekilde geçiren çocuk, okul dönemi oyunlarında da aktif bir rol alır. Çocukta var olan bu becerileri okul döneminde artık daha spesifik olarak yönlendirmek mümkündür. Çocuğun ilgisi ve yapabilirliği doğrultusunda, çocuğu, herhangi bir spor branşına yönlendirmek, hareket enerjisini atmasına yardımcı olmak, kendi bedenini tanıması ve kendi sınırlarını keşfetmesi adına ebeveynlere ve öğretmenlere büyük sorumluluk düşmektedir. Çocuklara hareket edebilecekleri alanlar yaratıp, hareketsizliğe sürükleyecek durumlara karşı önlemler alarak onları desteklemeleri çocuğum olumlu gelişimi açısından gerekmektedir.

Okul öncesinden oyunla başlayıp sonradan fiziki aktivitelerle ya da daha profesyonel bir şekilde sporla devam eden bu süreç içinde aktif rol alan çocuklar sosyal olarak da birçok beceriyi kazanacaklardır. Spor yaparken kendini tanıma firsatı bulacaklar, kendi sınırlılıklarını keşfedeceklerdir. Aynı zamanda sorumluluk alma, gruba dâhil olma, saygılı, hoşgörülü ve centilmen olma, kazanma-kaybetme gibi duyguları yaşayıp öğrenme, beraber çalışma ve kişiler arası iletişim becerilerini kazanma, kendini ifade etme ve özgüven geliştirme gibi olumlu sosyal etkilerinin olduğundan bahsedilebilecek olan sporun, vücut sağlığına faydalı olduğu da bilinen bir gerçektir.

$\mathrm{Bu}$ sonuçlar göz önünde bulundurulduğunda ebeveynlerin, çocukların yaşamlarına spor kültürünü dâhil etmesi onların gelişimi açısından önem arz etmektedir. Sağlıklı kişilik ve fizyolojik gelişimi desteklemek adına kullanabilecek en kolay yollardan birinin spor olduğu unutulmamalıdır. Bu nedenlerden dolayı bu makalede sporun psiko-motor ve sosyal gelişime katkısı ve önemi üzerinde durulmuştur.

Bu bilgilerden yola çıkarak; 
- Ailelerin çocuklarının sosyal becerilerini ve fiziksel sağlığını desteklemek adına spora yönlendirip, çocuklarında spor kültürü oluşturmaları için aileleri bilinçlendirme çalışmaları yapılabilir.

- Çocuklarda sosyal becerilerin desteklenmesinde okullarda öğretmenler için hizmet içi eğitim programları düzenlenebilir.

- Çocuklar doğal öğrenme ortamı içindeyken onları fiziki aktivitelerle destekleyip sosyal becerilerini de desteklemek adına bütünleştirilmiş etkinlikler kullanılabilir.

- Yetkili kurumlar çocuklar için oyun alanları oluşturmada, onları hareket etmeye ve bir arada bulunmaya teşvik edecek düzenlemeler yapabilir. 


\section{Kaynakça}

Arabacı, N., \& Çıtak, Ş. (2017). Okul Öncesi Dönemdeki Çocukların “"Oyun”" ve " "Açık Alan (Bahçe)" Etkinlikleri İle İlgili Görüşlerinin İncelenmesi ve Örnek Bir Bahçe Düzenleme Çaışması. Mediterranean Journal of Educational Research, 11(21), 28-43.

Bayhan, P. S., \& Artan, İ. (2009). Motor Gelişim. P. S. Bayhan \& İ. Artan (Editörler), Çocuk Gelişimi ve Eğitimi (ss. 168-190). İstanbul: MORPA Kültür Yayınları Ltd. Ş.

Çelik, A., \& Şahin, M. (2013). Spor Ve Çocuk Gelişimi. The Journal of Academic Social Science Studies International Journal of Social Science, 6(1), 467-478.

Culbertson, J. L., Newman, J. E., \& Willis, D. J. (2003). Childhood and adolescent psychologic development. Pediatric Clinics of North America, 50(4), 741-764. https://doi.org/10.1016/S00313955(03)00080-4

Demirci, E. (2007). Okul Öncesinde Psiko-motor Gelişim. Kafkas Üniversitesi.

Durualp, E., \& Aral, N. (2010). Altı Yaşındaki Çocukların Sosyal Becerilerine Oyun Temelli Sosyal Beceri Eğitiminin Etkisinin İncelenmesi. Hacettepe Üniversitesi Eğitim Fakültesi Dergisi, 39, $160-172$.

Findlay, L. (2006). Come Out and Play: Shyness in Childhood and Benefits of Sports Participation. Carleton University.

Gallahue, D. (1982). Phases And Stages Of Motor Development. In D. Gallahue (Ed.), Understanding Motor Development In Children (First Edit, pp. 135-254). New York: John Wiley \& Sons, Inc.

Gallahue, D., \& Ozmun, J. (1995). Fundamental Movement Abilities. In S. Spoolman (Ed.), Understanding Motor Development: Infant, Children Adolescents, Adults. (Third Edit, pp. 223404). Wisconsin-Iowa: Brown \& Benchmark.

Günindi, Y. (2010). Anasınıfina Devam Eden Altı Yaş Çocuklarına Uygulanan Sosyal Uyum Beceri Eğitimi Programının Çocukların Sosyal Uyum Becerilerinin Gelişimine Etkisi. Gazi Üniversitesi.

Güven, G. (2006). Kütahya'da Okul Öncesi Eğitim Kurumlarında Uygulanan Oyun Ve Spor Programlarının İncelenip Değerlendirilmesi. Dumlupınar Üniversitesi.

Hekim, M. (2016). Çocuklarda Beden Eğitimi, Spor Ve Oyun Etkinliklerine Katılımın Kemik Gelişimi Üzerine Etkilerinin Değerlendirilmesi. Gümüşhane Üniversitesi Sağlık Bilimleri Dergisi, 5(2), 6671.

Heper, E., Koca, C., Ertan, H., Kale, M., Terek, S., Karabudak, E., \& Ertan, H. (2012). Spor Bilimleri ile İlgili Kavramlar ve Sporun Tarihsel Gelişimi. H. Ertan (Ed.), Spor Bilimlerine Giriş (1. Bask1, ss. 11-12). Eskişehir: Anadolu Üniversitesi.

McClelland, M. M., \& Morrison, F. J. (2003). The emergence of learning-related social skills in preschool children. Early Childhood Research Quarterly, 18(2), 206-224. https://doi.org/10.1016/S0885-2006(03)00026-7

MEB. (2013). Okul Önces Eğitimi Programi. MEB.

Özer, D. S., \& Özer, K. (2016). 2-6 Yaş Döneminde-İlkkul Ve Ergenlik Döneminde Motor Gelişim. In D. S. Özer \& K. Özer (Editörler), Çocuklarda Motor Gelişim (9. Baskı, ss. 122-177). Ankara: Nobel Yayın.

Özyürek, A., Özkan, İ., Begde, Z., \& Yavuz, F. N. (2015). Okul Öncesi Dönemde Beden Eğitimi ve Spor. International Journal of Science Culture and Sport, (3), 479-488. https://doi.org/10.14486/IJSCS314

Şahin, S. (2016). 0-6Yaş Arası Çocukların Temel Gelişimsel Özellikleri: Fiziksel Ve Sosyal-Duygusal Gelişim. H. İ. Diken (Ed.), Erken Çocukluk Eğitimi (4.Bask1, ss. 170-208). Ankara: Pegem Yayıncilik.

Saka, T., Yıldız, Y., Tekbaş, Ö. F., \& Aydın, T. (2008). Genç Eerkeklerde Spor Okulu Eğitim Programlarının Bazı Antropometrik ve Fonksiyonel Testler Üzerine Etkisi. Niğde Üniversitesi Beden Eğitimi ve Spor Bilimleri Dergisi, 2(1), 1-8.

Salar, B., Hekim, M., \& Tokgöz, M. (2012). 15-18 Yaş Grubu Takım ve Ferdi Spor Yapan Bireylerin Duygusal Durumlarının Karşılaştırılması. Mehmet Akif Ersoy Üniversitesi Sosyal Bilimler Enstitüsü Dergisi, O(6), 123-135. https://doi.org/10.20875/SB.47129

Şenduran, F. (2008). Sporcu Olan Ve Sporcu Olmayan Ortaöğretim Öğrencilerinin Uyum Becerileri. In 10. Uluslararası Spor Bilimleri Kongresi (ss. 189-191). Karabük. 
Şimşek, S. (1998). Illköğretim 8. Sinıf Beden Ĕ̈itimi Dersinin Öğrencilerin Psiko-motor Gelişimine Katkısı Konusunda Beden Ĕ̈itimi Öğretmenleri ve Öğrencilerin Görüşleri. Pamukkale Üniversitesi.

Tepeli, K. (2012). Motor (Hareket) Gelişimi. In M. E. Deniz (Ed.), Erken Çocukluk Döneminde Gelişim (4. Bask1, ss. 91-124). Ankara: Maya Akademi.

Tüfekçioğlu, E., \& Ayça, İ. B. (2008). Okul öncesi 4 - 6 yaş çocuklarında algısal motor gelişim programlarının denge ve çabukluk üzerine etkisi. Uluslararası İnsan Bilimleri Dergisi, 5(2), 1-11.

Valentine, G., \& Mckendrickt, J. (1997). Children's Outdoor Play: Exploring Parental Concerns About Children's Safety and the Changing Nature of Childhood. Geoforum, 28(2), 219-235. https://doi.org/10.1016/S0016-7185(97)00010-9

Yılmaz, M. O., \& Bozkurt, S. (2017). Oyun ve Fiziki Etkinlikler Dersinin İlkokul Öğrencilerinin Motorik Özelliklerinin Gelişimine Etkisi. Marmara Üniversitesi Spor Bilimleri Dergisi, 2(2), 4350. https://doi.org/10.22396/sbd.2017.30 